\title{
Trimodality therapy of esophagectomy plus neoadjuvant chemoradiotherapy improves the survival of clinical stage II/III esophageal squamous cell carcinoma patients
}

\author{
YOSHINORI FUJIWARA ${ }^{1}$, REIGETSU YOSHIKAWA ${ }^{2}$, NORIHIKO KAMIKONYA ${ }^{3}$, \\ TSUYOSHI NAKAYAMA ${ }^{1}$, KOTARO KITANI ${ }^{1}$, MASANORI TSUJIE $^{1}$, MASAO YUKAWA $^{1}$, \\ MASATOSHI INOUE $^{1}$ and TAKEHIRA YAMAMURA ${ }^{4}$
}

\author{
${ }^{1}$ Department of Digestive Surgery, Nara Hospital, Kinki University School of Medicine, Nara; ${ }^{2}$ Department of Surgery, \\ Kanzaki Hospital, Hyogo; Departments of ${ }^{3}$ Radiology, and ${ }^{4}$ Surgery, Hyogo College of Medicine, Nishinomiya, Japan
}

Received March 3, 2012; Accepted May 7, 2012

DOI: $10.3892 /$ or.2012.1847

\begin{abstract}
The prognosis of advanced esophageal cancer patients is poor. Trimodality therapy of surgical resection plus neoadjuvant chemoradiotherapy (CRT) has been developed to improve survival through locoregional control, leading to prevention of micrometastasis. We investigated whether or not neoadjuvant CRT led to survival benefits in TNM stage II/ III esophageal cancer patients. We retrospectively reviewed 62 patients with stage II or III esophageal squamous cell carcinoma (ESCC) treated with neoadjuvant CRT. All patients received esophagectomy 4-7 weeks after CRT consisting of 40 Gy irradiation and chemotherapy $\left(5-\mathrm{FU}, 500 \mathrm{mg} / \mathrm{m}^{2} / \mathrm{day}\right.$, days 1-5 and cisplatin, 10-20 mg/body, days 1-5). Clinical response and survival rates were analyzed using Kaplan-Meier methods, with $\mathrm{P}<0.05$ considered as significant. The clinical effect rate of CRT for both primary tumors and metastatic nodes was $82.3 \%$. Operative and hospital mortality rates were 1.65 and $6.5 \%$, respectively. The 3-year overall survival (OS) and disease-free survival (DFS) rates were 52.6 and $49.2 \%$, respectively. A significant difference was noted between stages II and III for both OS and DFS. The 5-year OS rates were $64.2 \%$ for stage II, $33.1 \%$ for stage III (T4 and non-T4) and $46.9 \%$ for stage III (non-T4 only) patients. The depth of tumor invasion (T3 vs. T4), resectability (R0 vs. R1, R2), lymph node metastasis (positive vs. negative), and the effect of CRT were proven to be independent prognostic factors for univariate analysis, with resectability and the effect of CRT for multivariate analysis. These data suggest that CRT in stage II/III (non-T4) ESCC patient contributed to tumor shrinkage, leading to higher resectability and longer survival. Neoadjuvant CRT appears to be a promising option for these patients.
\end{abstract}

Correspondence to: Dr Yoshinori Fujiwara, Department of Digestive Surgery, Nara Hospital, Kinki University School of Medicine, 1248-1, Otoda-cho, Ikoma, Nara 630-0293, Japan

E-mail: yyfujiwara@nifty.com

Key words: chemoradiotherapy, esophagectomy, survival

\section{Introduction}

Esophageal cancer is one of the most aggressive malignancies and is associated with a poor prognosis because of early metastasis to lymph nodes as well as distant organs (1-3). Esophageal squamous cell carcinomas (ESCCs) are far more common in Asian countries including Japan, whilst adenocarcinomas of the lower third of the esophagus are often seen in Western countries. In 2005, 11,182 Japanese died from esophageal cancer according to the Japanese Ministry of Health, Labour and Welfare. Surgery has been considered the treatment of choice for patients with locoregionally confined esophageal carcinoma. However, the 5-year survival rate is less than $25 \%$ worldwide (4-6).

In Japan, the survival rate has been improving during the past two decades since three field lymphadenectomy was advocated by Isono et al (7) and Akiyama et al (8) and it is now widely performed. According to the comprehensive registry of esophageal cancer in Japan (3rd edition) (9), the current survival rates of clinical stage IIA, IIB and III patients categorized by UICC (10) are reportedly 47.5, 45.1 and 33.3\%, respectively. These results were rather disappointing in spite of vigorous lymphadenectomy. The bottom-line in esophageal cancer treatment is locoregional control, and the locoregional failure rate after esophagectomy has been reported to be approximately $30 \%$ for patients who received $\mathrm{R} 0$ resection (11). Likewise, the locoregional recurrence rate (which included persistent disease and locoregional recurrence) is 50-55\% after definitive chemoradiotherapy (CRT) without surgery $(12,13)$.

To resolve these locoregional failures, multimodality therapy involving the combination of surgery and CRT has been developed. The most common approach is preoperative CRT followed by esophagectomy, called trimodality therapy $(14,15)$. This approach offers the potential advantage of tumor downstaging, less dissemination of malignant cells during surgery and prevention of micrometastasis. Nine randomized trials have been performed in patients with locoregionally confirmed esophageal cancer who received preoperative CRT compared with surgery alone (15-23). Two of these 9 studies showed an improved outcome despite a small number of 
patients (15), while the other studies showed no survival benefits in the trimodality therapy group. Therefore, the benefits of preoperative CRT are still controversial.

There is no randomized study ongoing or being planned related to preoperative CRT of ESCC in Japan because of technical difficulties both in surgery and radiotherapy. Since 1996, we have introduced preoperative CRT using 5-fluorouracil (5-FU) and cisplatin (CDDP) combined with radical surgery for the treatment of advanced esophageal cancers, and have reported increased resectability, a reduced incidence of both local recurrence and distant metastasis, and a more favorable prognosis for CRT responders (24). In the present study, we re-evaluated the feasibility and efficacy of preoperative CRT and investigated whether a survival benefit was obtained for stage II/III ESCC patients receiving neoadjuvant CRT.

\section{Patients and methods}

Patients. We performed a retrospective review of 80 consecutive patients with esophageal cancer who received esophagectomy after neoadjuvant CRT between August 1997 and October 2007 at the Department of Surgery, Hyogo College of Medicine, Japan. Sixty-two of the 80 patients had clinical stage II or III disease based on the UICC TNM Classification of Malignant Tumors (5th edition) (10), as determined by CT scan and/or endoscopic ultrasound examination findings, and underwent concurrent CRT followed by esophagectomy.

The eligibility criteria of this study were as follows: $<80$ years old, adequate organ function $(\mathrm{WBC} \geq 3500, \mathrm{Hb} \geq 10 \mathrm{~g} / \mathrm{dl}$, ALT/AST $\leq 2 x$ upper limit of normal, platelets $\geq 100,000$, serum creatinine $\leq 1.3$ ), and a performance status (Eastern Cooperative Oncology Group) of $<2$ at the time of admission (Table I).

Preoperative radiotherapy was performed for 5 days per week (Monday to Friday, 2 Gy/day) using a linear accelerator (Mevatron KD2; Siemens, Germany). The radiation field encompassed the primary tumor volume (as defined by endoscopy, esophagography and CT scan) with a $3-\mathrm{cm}$ margin in each cephalad and caudal direction and 4-cm horizontal margins. If the lymph nodes metastasis was detected by a CT scan, the radiation field was extended to include the primary tumor and metastatic lesions. The patients received 20 fractions of $2 \mathrm{~Gy}$ for a total of $40 \mathrm{~Gy}$ of radiation. Concurrent chemotherapy consisted of $5-\mathrm{FU}\left(500 \mathrm{mg} / \mathrm{m}^{2} /\right.$ day $)$ administration for a $120-\mathrm{h}$ continuous intravenous infusion starting on Day 1 and CDDP (15-20 mg/day) for a 2-h intravenous infusion on Days 1-5, repeated after 3 weeks.

Two to three weeks after the completion of radiotherapy, the effects of CRT on the primary tumor and metastatic nodes were assessed using chest CT scanning, barium esophagography, and/or upper gastrointestinal endoscopy. The response to therapy was defined as confirmed by esophagography or esophagoscopy and CT scans according to the criteria of the Japanese Society of Esophageal Disease (9th edition) (25): i) complete response (CR), $100 \%$ regression of cancer; ii) partial response $(\mathrm{PR}),>50 \%$ regression of the primary tumor and metastatic nodes; iii) progressive disease (PD), defined as increase of $25 \%$ in the size of the primary tumor or metastatic nodes or the appearance of new lesions; and iv) no change (NC) defined as a decrease of $<50 \%$ in the size of the primary tumor and metastatic nodes and no evidence of tumor progression.
Table I. Patient characteristics.

Stage II $(n=30)$ Stage III $(n=32)$

\begin{tabular}{lcc}
\hline Age, mean & 60.33 & 61.32 \\
Male/Female & $26 / 4$ & $24 / 8$ \\
Location of primary tumor & & \\
Cervical & 3 & 2 \\
Upper thoracic & 22 & 4 \\
Middle thoracic & 5 & 17 \\
Lower thoracic & & 7 \\
Abdominal & & 2 \\
T-classification & 30 & 15 \\
T3 & & 17 \\
T4 & & \\
N-classification & 27 & 16 \\
N0 & 3 & \\
N1 & & \\
\hline
\end{tabular}

Toxicities were classified according to NCI CTC Guidelines, version 3 (26).

Esophagectomy was planned for 4-7 weeks after the completion of CRT. Most patients underwent thoracotomy, laparotomy, and cervicotomy to perform esophagectomy with 2- or 3-fields lymphadenectomy, and gastroesophageal anastomosis at the left side of the neck. Radical resection (R0) was defined as the removal of all macroscopic tumors, no evidence of distant metastasis, the absence of a microscopic residual tumor, free resection margins, and lymphadenectomy extending beyond the involved nodes. Resection was defined as non-radical when a microscopic (R1) or macroscopic (R2) residual tumor was found according to the TNM criteria (10). Informed consents were obtained in all patients.

Statistical analysis. Overall survival (OS) was defined as the time from the data of initial treatment to patient death or the data of the last available information on the vital status. Disease-free survival (DFS) was defined as the length of time after treatment during which no cancer was found. Differences between the cumulative survival rates of the patient groups were calculated by the log-rank test for comparison using Kaplan-Meier survival curves. Statistical significance was considered at values of $\mathrm{P}<0.05$. Univariate analyses were used to examine the patients' characteristics and other prognostic factors. Multivariate analyses were employed for the identification of prognostic factors with the Cox proportional hazard model. Statistical analyses were carried out using the Statistica software, version 06J (StatSoft, Tulsa, OK, USA), and SPSS version 16 (SPSS, Tokyo, Japan).

\section{Results}

Patient characteristics. The patient characteristics of this study are summarized in Table I. All tumors were histologically confirmed to be ESCC. The gender was biased toward males (male/female, 50:12). The mean age was 60.83 years 
Table II. Effects of CRT for primary tumor and metastatic nodes.

Clinical response rate

\begin{tabular}{lccc} 
Response & Primary tumor & Metastatic nodes & (Primary tumor and metastatic nodes) \\
\hline $\mathrm{CR}, \mathrm{n}$ & 14 & 4 & 14 \\
$\mathrm{PR}, \mathrm{n}$ & 38 & 10 & 37 \\
$\mathrm{NC}, \mathrm{n}$ & 9 & 4 & 9 \\
PD, $\mathrm{n}$ & 1 & 2 & 2 \\
Response rate $(\%)$ & 83.9 & 70 & 82.3 \\
\hline
\end{tabular}

$\mathrm{CR}$, complete response; $\mathrm{PR}$, partial response; $\mathrm{NC}$, no change; $\mathrm{PD}$, progressive disease.

Table III. Postoperative complications after esophagectomy for patients with stage II, III esophageal cancer.

\begin{tabular}{ll}
\hline Complications & $\mathrm{n}(\%)$ \\
\hline Anastomotic leakage & $6(9.7)$ \\
Recurrent nerve palsy & $4(6.5)$ \\
Respiratory failure & $4(6.5)$ \\
Pleural effusion & $2(3.2)$ \\
Sepsis & $1(1.6)$ \\
Arrhythmia & $1(1.6)$ \\
Myocardial infarction & $1(1.6)$ \\
SMA occlusion & $1(1.6)$
\end{tabular}

SMA, superior mesenteric artery.

old. Fifty-eight of the 62 patients had tumors in the thorax. Seventeen stage III patients had tumors infiltrating through the esophageal wall to adjacent structures (T4, 53.1\% of stage III patients). Nineteen patients $(30.65 \%)$ had lymph nodes metastasis on a CT scan at the time of diagnosis.

Response and toxicities. The clinical response to CRT is summarized in Table II. The clinical response (CR+PR) rates of CRT for the primary tumor and metastatic nodes were 83.9 and $70 \%$, respectively. The clinical response of both the primary tumor and metastatic nodes was $82.3 \%$. Major toxicities of treatment are summarized and laboratory findings were obtained from 59 patients. Leukocytopenia and thrombocytopenia of grade 3 or higher were noted in 33.9 and $5.1 \%$ of the patients, respectively. Liver dysfunction of grades 1 or 2 was noted in $11.8 \%$. Fatigue, stomatitis and nausea of grade 1 or 2 were noted in 36,10 and $26 \%$ of the cases, respectively. Other toxicities were found in 50 patients. CRT-related death was not reported.

Surgery and postoperative complications. All patients underwent esophagectomy after the completion of CRT. Radical $\mathrm{R} 0$ resection was achieved in 45 patients $(72.6 \%)$, $\mathrm{R} 1$ resection with a microscopic residual tumor was achieved in 8 $(12.9 \%)$, and $\mathrm{R} 2$ resection with a macroscopic residual tumor in $9(14.5 \%)$. The reasons for the failure of radical resection

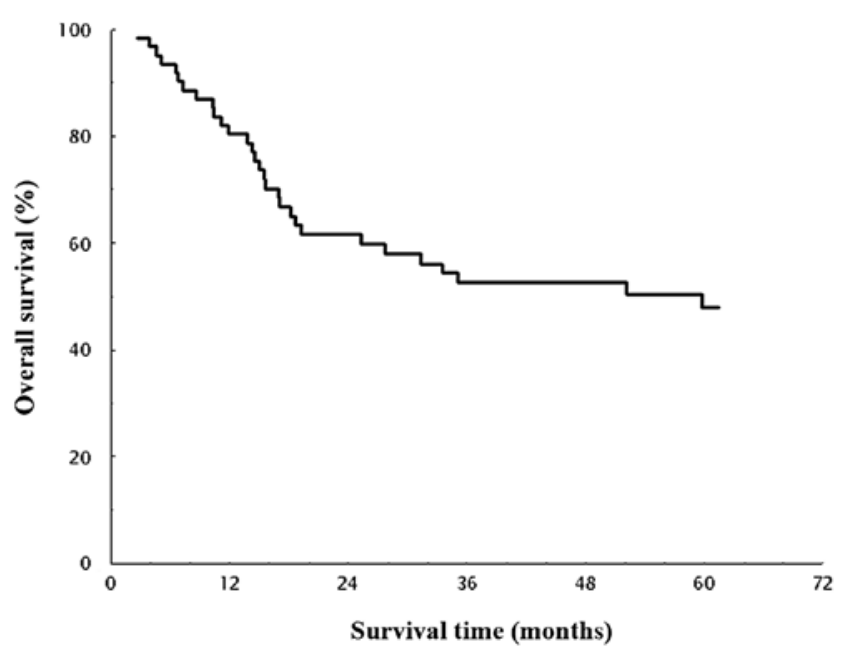

Figure 1. Overall survival in stage II and III esophageal cancer patients.

leading to $\mathrm{R} 2$ resection were a residual primary tumor in 4 patients, metastatic nodes in 3, and the occurrence of new distant metastasis during neoadjuvant CRT in 2. Postoperative complications are shown in Table III. One patient died from occlusion of the superior mesenteric artery (SMA) within 4 weeks of surgery, corresponding to $1.6 \%$ of the operative mortality. Three patients died of respiratory failure including 2 metastatic lung cancers within 3 months after the operation corresponding to $6.5 \%$ of hospital mortality.

Pathological response of the primary tumor. Fifteen of the 62 patients $(24.2 \%)$ had no residual tumor in the resected esophagus, representing pathological CR.

Survival. The mean follow-up period was 46 months (3-169 months). OS in all patients is shown in Fig. 1. The median survival time (MST) for OS was 53.3 months, and the estimated 1-, 2-, 3- and 5-year survival rates were 80.4, 61.6, 52.6, and $48.0 \%$, respectively. DFS in all patients is shown in Fig. 2. The MST for DFS was 23.8 months, and the estimated 1-, 2-, 3 - and 5-year survival rates were 64.5, 52.7, 49.2 and 47.1\%, respectively.

Comparison of survival between T3 and T4 patients was additionally performed. The estimated 5-year OS rates were $63.3 \%$ for T3 patients and $28.3 \%$ for T4 patients. Similarly, 


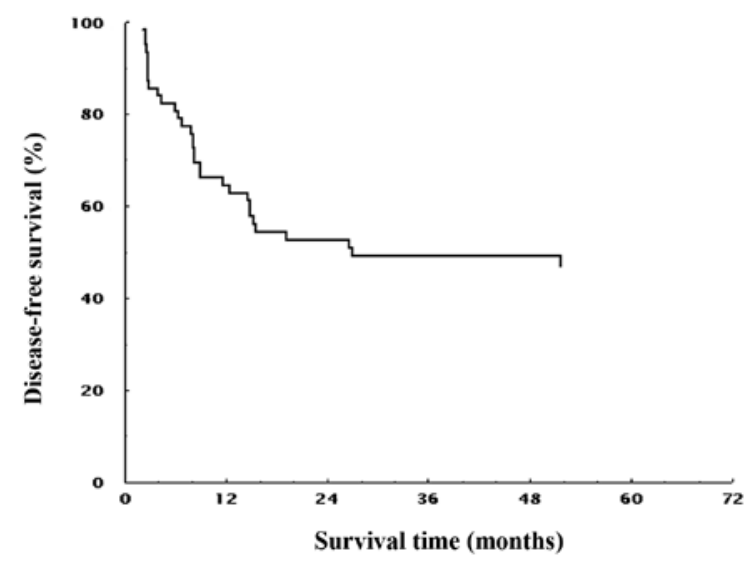

Figure 2. Disease-free survival in stage II and III esophageal cancer patients.

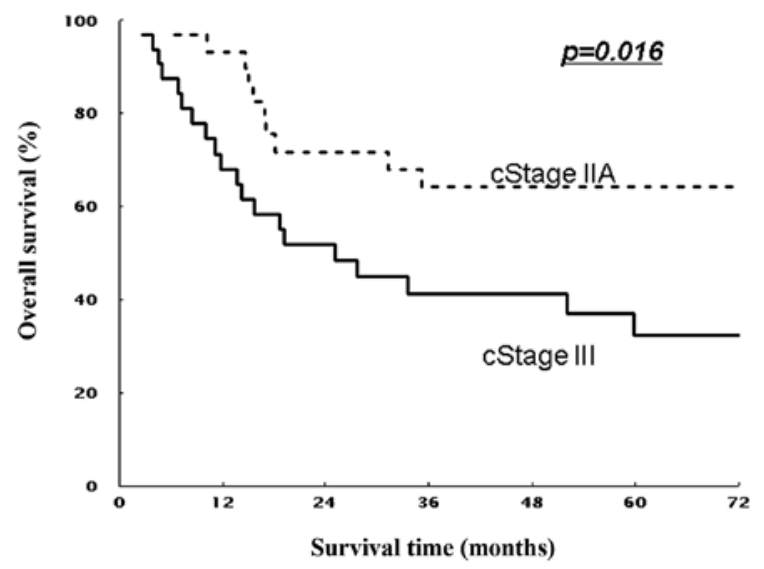

Figure 3. Overall survival in stage II and III patients who received preoperative chemoradiation.

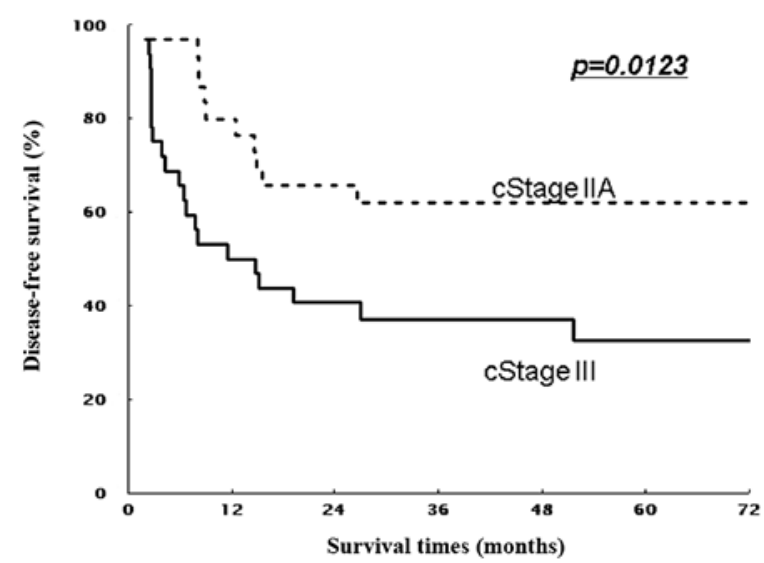

Figure 4. Disease-free survival in stage II and III patients who received preoperative chemoradiation.

the 5-year DFS rates were $61.1 \%$ for T3 patients and $26.1 \%$ for $\mathrm{T} 4$ patients. The clinical T3 patients showed significantly longer OS and DFS compared with clinical T4 $(\mathrm{P}=0.006$ in OS and $\mathrm{P}=0.002$ in DFS, respectively). Furthermore, the survival rates between different stages were compared according to the UICC Classification. The estimated 5-year OS rates were $64.2 \%$ for

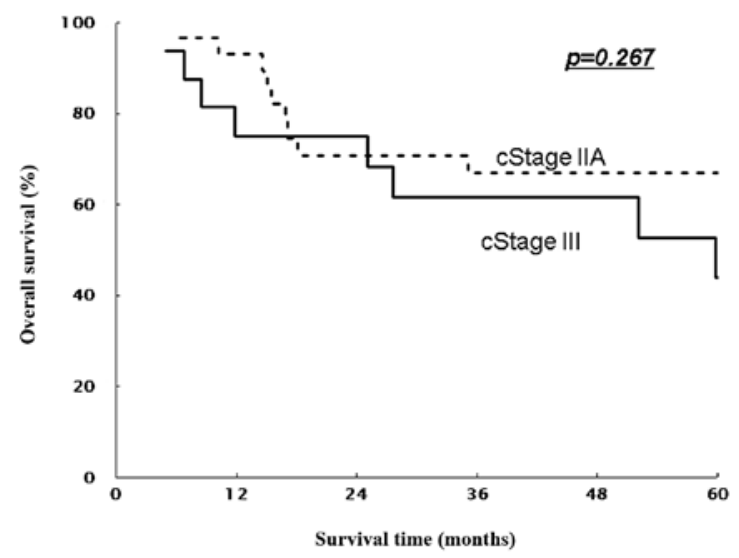

Figure 5. Overall survival in stage II and III patients excluding T4 patients who received preoperative chemoradiation.

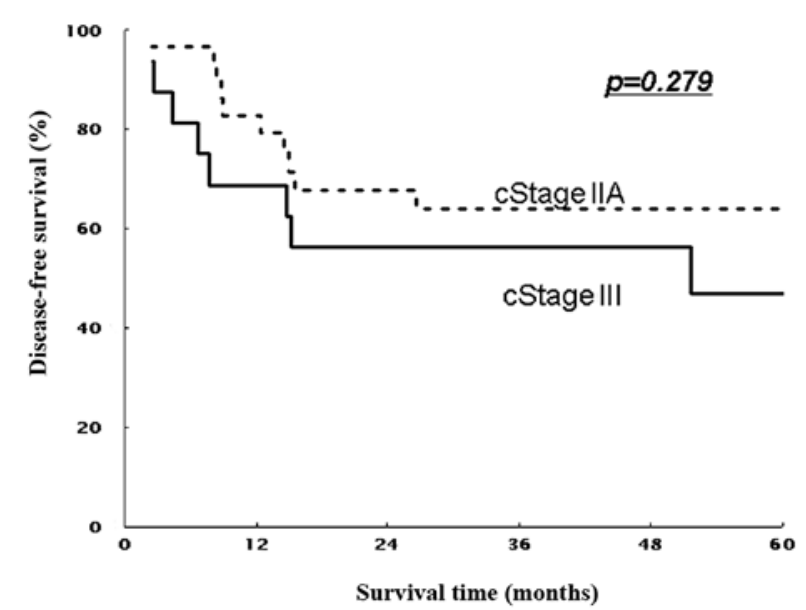

Figure 6. Disease-free survival in stage II and III patients excluding T4 patients who received preoperative chemoradiation.

stage II and $33.1 \%$ for stage III (all T), and $46.9 \%$ for stage III (non-T4) patients ( $\mathrm{P}=0.016$ and $\mathrm{P}=0.267$, Figs. 3 and 5). Similarly, 5-year DFS rates were $61.9 \%$ for stage II, $32.3 \%$ for stage III (all $\mathrm{T}$ ), and $43.8 \%$ for stage III (non-T4) patients ( $\mathrm{P}=0.011$ and $\mathrm{P}=0.297$; Figs. 4 and 6). Patients with stage II showed significantly longer OS and DFS than those with stage III. In subgroup analysis for stage III patients, the estimated 5-year OS and DFS were 46.9 and $43.9 \%$ for $\mathrm{T} 3$, and 20.3 and $18.8 \%$ for T4, respectively ( $\mathrm{P}=0.045$ and $\mathrm{P}=0.035$, Figs. 5 and 6 ).

Univariate analysis for overall survival in stage II/III esophageal cancer patients is shown in Table IV. Lymph node metastasis, depth of tumor invasion and resectability showed significant differences in the prognostic value $(\mathrm{P}<0.01)$. Furthermore, the patients who were CRT responders showed significantly longer OS compared to those who were not $(\mathrm{P}<0.001)$. Using multivariate analysis, resectability and the effect of CRT were independent prognostic factors for OS (Table V).

\section{Discussion}

We have previously reported that preoperative CRT contributes to improve the resectability in patients with ESCC, and 
Table IV. Univariate analysis for OS.

\begin{tabular}{|c|c|c|c|c|}
\hline Characteristics & No. of patients & Hazard ratio & OS P-value & $95 \% \mathrm{CI}$ \\
\hline \multicolumn{5}{|l|}{ Age (years) } \\
\hline$<70$ & 48 & 1.367 & 0.53 & $0.514-3.65$ \\
\hline$\geq 70$ & 14 & & & \\
\hline \multicolumn{5}{|l|}{ Gender } \\
\hline Male & 51 & 0.841 & 0.489 & $0.515-1.373$ \\
\hline Female & 11 & & & \\
\hline \multicolumn{5}{|l|}{ Effect of CRT } \\
\hline Effective & 51 & 0.29 & $0.00051^{\mathrm{b}}$ & $0.091-0.476$ \\
\hline Not effective & 11 & & & \\
\hline \multicolumn{5}{|c|}{ Lymph nodes metastasis } \\
\hline Positive & 19 & 2.855 & $0.00075^{\mathrm{b}}$ & $1.3-6.27$ \\
\hline Negative & 43 & & & \\
\hline \multicolumn{5}{|c|}{ Depth of tumor invasion } \\
\hline $\mathrm{T} 3$ & 45 & 3.463 & $0.0078^{b}$ & $1.55-7.719$ \\
\hline $\mathrm{T} 4$ & 17 & & & \\
\hline \multicolumn{5}{|l|}{ Tumor location ${ }^{\mathrm{a}}$} \\
\hline Upper & 9 & 0.767 & 0.628 & $0.262-2.241$ \\
\hline Lower & 53 & & & \\
\hline \multicolumn{5}{|c|}{ Counts of lymph nodes metastasis } \\
\hline$>4$ & 6 & 23.77 & $0.00001^{\mathrm{b}}$ & $6.93-81.57$ \\
\hline$<3$ & 56 & & & \\
\hline \multicolumn{5}{|l|}{ Resectability } \\
\hline R0 & 45 & 10.23 & $0.00001^{\mathrm{b}}$ & $4.34-24.1$ \\
\hline $\mathrm{R} 1, \mathrm{R} 2$ & 17 & & & \\
\hline \multicolumn{5}{|c|}{ Pathological complete response } \\
\hline Yes & 15 & 25.17 & $0.005^{\mathrm{b}}$ & $6.83-43.5$ \\
\hline No & 47 & & & \\
\hline
\end{tabular}

${ }^{\mathrm{a}}$ Upper, tumor located above the bifurcation; lower, below the bifurcation. ${ }^{\mathrm{b}}$ Statistically significant.

Table V. Multivariate analysis of factors associated with OS of ESCC.

\begin{tabular}{lllc}
\hline & P-value & HR & 95\% CI \\
\hline Age & 0.28 & 1.633 & $0.671-3.972$ \\
Lymph nodes metastasis & 0.659 & 0.819 & $0.337-1.990$ \\
Depth of tumor invasion & 0.126 & 2.155 & $0.805-5.770$ \\
Clinical stage & 0.752 & 1.176 & $0.432-3.199$ \\
Resectability & $0.001^{\mathrm{a}}$ & 5.072 & $2.059-12.497$ \\
Effect of CRT & $0.01^{\mathrm{a}}$ & 0.279 & $0.106-0.733$ \\
\hline
\end{tabular}

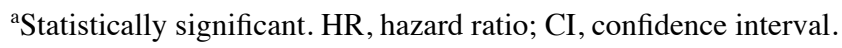

that surgical esophagectomy remains the standard therapy for CRT responders (24). In this study, we focused on the characteristics of the UICC stage II/III ESCC, and analyzed whether this trimodality therapy combined with neoadju- vant CRT and esophagectomy improved the outcome of the patients.

This retrospective study showed that the 5-year OS rates of cstage II/III esophageal cancer patients were 64.2 and $33.1 \%$, respectively. On the other hand, those of UICC clinical stage II/III patients after esophagectomy were reported to be from $47.5 \%$ (stage IIA) to $33.3 \%$ (stage III) by the Comprehensive Registry of Esophageal Cancer in Japan (9). These data suggest that the addition of neoadjuvant CRT is beneficial regarding the outcome of stage II patients. We failed to show the survival benefit of neoadjuvant CRT in stage III patients. However, this is thought to be due to the biased demographics in our study; more advanced T4 patients comprised approximately $50 \%$ in stage III patients. Actually, subgroup analysis showed that trimodality therapy improved the outcome of T3 more than T4 patients in stage III.

There have been nine randomized trials of preoperative CRT following surgery vs. surgery alone (15-23). Of the nine randomized trials, three studies showed survival benefits in preoperative CRT group compared to those receiving surgery 
alone $(15,22,23)$. However, patient numbers in two randomized trials were too small to be evaluated objectively $(15,23)$. Notably, a large-scale study by Burmeister et al revealed that 5-FU/CDDP (FP) plus radiation (35 Gy) followed by esophagectomy for ESCC improves DFS, but not for all patients including those with adenocarcinoma (22). This report has encouraged us to continue trimodality therapy for ESCC in Japan. In any case, it is difficult to evaluate these randomized studies unitarily, because all these randomized phase III reports have flaws due to their wide variation in CRT protocols, short follow-up duration, different histological types, different stages, and different operative procedures. Moreover, we are urged to standardize the regimen of chemotherapeutic agents and radiation dose. Courrech Staal et al systematically reviewed the benefits and risks of neoadjuvant CRT for esophageal cancer, and reported that FP was the widely used mainstay in CRT regimens all over the world (27). Therefore, it sounds reasonable that the standard chemotherapeutic regimen needs to be established based on FP regimen in Asia as well as in Western countries. The standard regimen of definitive CRT advocated by Intergroup INT0123 (RTOG9405) consists of 2 cycles of 5 -FU $\left(1,000 \mathrm{mg} / \mathrm{m}^{2} / 24 \mathrm{~h}\right.$ for 4 days) and CDDP $\left(100 \mathrm{mg} / \mathrm{m}^{2} /\right.$ bolus on Day 1) with 50.4 Gy irradiation (13). In Japan, the regimen of neoadjuvant CRT should also be determined on the basis of the INT123 study, and the concurrent radiation dose should be discussed considering the safety of surgery. In this study, CRT consists of 5-FU $\left(500 \mathrm{mg} / \mathrm{m}^{2} / 24 \mathrm{~h}\right.$ for 5 days) and CDDP (15-20 mg/bolus for 5 days) with 40 Gy irradiation as a result of discussion with radiologists. The chemotherapeutic and radiation doses in our regimen were lower than those in the INT0123 study, but our setting dose was sufficient to show the efficacy and safety with tolerability. Hospital mortality after esophagectomy following CRT was reported to be $5.2 \%$ in Courrech Staal's review, which was compatible with that in our study (27).

The clinical response rates were assessed in this study. Those of the primary tumor ranged from 59 to $87 \%$ in previous preoperative randomized or non-randomized studies $(17,18,21,28,29)$. Meanwhile, our study showed that the clinical response rate using the Japanese Guidelines for Esophageal Disease was $83.9 \%$ for the primary tumor and $70 \%$ for metastatic nodes.

Regarding the radiation field, the optimal radiation field design remains controversial (30-34). Hsu et al (30) compared the patients with AJCC stage II/III ESCC undergoing preoperative CRT (median, $36 \mathrm{~Gy}$ ) followed by radical esophagectomy with or without elective nodal irradiation (ENI). As a result, ENI reduced the M1a failure rate, but was not associated with improved outcomes in the patients undergoing preoperative CRT. Zhao et al (33) also evaluated 3D-CRT (irradiating only the primary tumor and positive lymph nodes) for ESCC, and concluded that the omission of elective nodal irradiation was not associated with a significant failure in lymph node regions not included in the planned target volume. In our study, we planned a radiation field including both the primary tumor and metastatic lymph nodes which were identified by an enhanced CT scan. Namely, we planned the irradiation field minimally to prevent operative and postoperative complications. Consequently, CRT minimized postoperative complications as we expected and improved the prognosis beyond our expectations, especially with the marked clinical response for metastatic nodes. In China, Zhao et al also used the same radiation field setting (33). In this way, the minimum setting for the primary tumor and metastatic nodes may be promising to achieve fewer complications and more prognostic benefits.

A recent meta-analysis revealed that a significant survival benefit for neoadjuvant CRT was evident for patients with resectable esophageal cancer with no increase in the morbidity rate [hazard ratio (HR), 0.81], and that definitive CRT did not demonstrate any survival benefit over other curative strategies (35). Intriguingly, neoadjuvant chemotherapy (without radiation) did not show any survival benefit (HR, 0.93). In Japan, preoperative chemotherapy with FP has been regarded as the standard treatment for patients with stage II/III (non-T4) ESCC by the JCOG 9204 and 9907 trials $(36,37)$. However, some critical problems were pointed out in these prospective randomized studies. First, there was a significant difference in subject numbers between pre- and postoperative chemotherapy groups $(\mathrm{P}=0.04)$ Secondly, patients with the $\mathrm{pN} 0$ status did not undergo postoperative chemotherapy in reality. Therefore, future clinical trials should resolve these above-mentioned problems. The 5-year OS in stage II/III (T3) patients in our study was higher than that in the JCOG study (63.3 vs. 55\%, respectively). We strongly propose that preoperative CRT be included in the next JCOG study to evaluate the efficacy of CRT more objectively in Japan.

In conclusion, preoperative CRT for cstage II/III (non-T4) ESCC patients contributed to high response rates for both the primary tumor and metastatic nodes and showed satisfactory outcome with tolerable morbidity and mortality. A phase II study is needed to better clarify the standard neoadjuvant CRT regimen through a large prospective randomized trial.

\section{References}

1. Goseki N, Koike M and Yoshida M: Histopathologic characteristics of early stage esophageal carcinoma. A comparative study with gastric carcinoma. Cancer 69: 1088-1093, 1992.

2. Roth JA and Putnam JB Jr: Surgery for cancer of the esophagus. Semin Oncol 21: 453-461, 1994.

3. Sugimachi K, Inokuchi K, Kuwano H, Kai H, Okamura T and Okudaira Y: Patterns of recurrence after curative resection for carcinoma of the thoracic part of the esophagus. Surg Gynecol Obstet 157: 537-540, 1983.

4. Salazar JD, Doty JR, Lin JW, et al: Does cell type influence postesophagectomy survival in patients with esophageal cancer? Dis Esophagus 11: 168-171, 1998.

5. Ando N, Ozawa S, Kitagawa Y, Shinozawa Y and Kitajima M: Improvement in the results of surgical treatment of advanced squamous esophageal carcinoma during 15 consecutive years. Ann Surg 232: 225-232, 2000.

6. Earlam R and Cunha-Melo JR: Oesophogeal squamous cell carcinoms: II. A critical view of radiotherapy. Br J Surg 67: 457-461, 1980

7. Isono K, Sato H and Nakayama K: Results of a nationwide study on the three-field lymph node dissection of esophageal cancer. Oncology 48: 411-420, 1991.

8. Akiyama H, Tsurumaru M, Udagawa $H$ and Kajiyama $Y$ : Radical lymph node dissection for cancer of the thoracic esophagus. Ann Surg 220: 364-372, 1994

9. Ozawa S, Baba H, Tachimori Y, et al: Comprehensive registry of esophageal cancer in Japan, 2003. Esophagus 8: 9-29, 2011.

10. International Union Against Cancer (UICC): TNM Classification of malignant Tumours. Sobin LH, Gospodarowicz MK, Wittekind C (eds). 5th edition. John Wiley \& Sons, Inc., New York, 1997.

11. Kelsen DP, Ginsberg R, Pajak TF, et al: Chemotherapy followed by surgery compared with surgery alone for localized esophageal cancer. N Engl J Med 339: 1979-1984, 1998. 
12. Cooper JS, Guo MD, Herskovic A, et al: Chemoradiotherapy of locally advanced esophageal cancer: long-term follow-up of a prospective randomized trial (RTOG 85-01). Radiation Therapy Oncology Group. JAMA 281: 1623-1627, 1999.

13. Minsky BD, Pajak TF, Ginsberg RJ, et al: INT 0123 (Radiation Therapy Oncology Group 94-05) phase III trial of combinedmodality therapy for esophageal cancer: high-dose versus standard-dose radiation therapy. J Clin Oncol 20: 1167-1174, 2002.

14. Urba SG, Orringer MB, Perez-Tamayo C, Bromberg J and Forastiere A: Concurrent preoperative chemotherapy and radiation therapy in localized esophageal adenocarcinoma. Cancer 69: 285-291, 1992.

15. Walsh TN, Noonan N, Hollywood D, Kelly A, Keeling N and Hennessy TP: A comparison of multimodal therapy and surgery for esophageal adenocarcinoma. N Engl J Med 335: 462-467, 1996.

16. Nygaard K, Hagen S, Hansen HS, et al: Pre-operative radiotherapy prolongs survival in operable esophageal carcinoma: a randomized, multicenter study of pre-operative radiotherapy and chemotherapy. The second Scandinavian trial in esophageal cancer. World J Surg 16: 1104-1110, 1992.

17. Le Prise E, Etienne PL, Meunier B, et al: A randomized study of chemotherapy, radiation therapy, and surgery versus surgery for localized squamous cell carcinoma of the esophagus. Cancer 73 1779-1784, 1994.

18. Apinop C, Puttisak P and Preecha N: A prospective study of combined therapy in esophageal cancer. Hepatogastroenterology 41: 391-393, 1994

19. Bosset JF, Gignoux M, Triboulet JP, et al: Chemoradiotherapy followed by surgery compared with surgery alone in squamouscell cancer of the esophagus. N Engl J Med 337: 161-167, 1997.

20. Urba SG, Orringer MB, Turrisi A, Iannettoni M, Forastiere A and Strawderman M: Randomized trial of preoperative chemoradiation versus surgery alone in patients with locoregional esophageal carcinoma. J Clin Oncol 19: 305-313, 2001.

21. Lee JL, Park SI, Kim SB, et al: A single institutional phase III trial of preoperative chemotherapy with hyperfractionation radiotherapy plus surgery versus surgery alone for resectable esophageal squamous cell carcinoma. Ann Oncol 15: 947-954 2004.

22. Burmeister BH, Smithers BM, Gebski V, et al: Surgery alone versus chemoradiotherapy followed by surgery for resectable cancer of the oesophagus: a randomised controlled phase III trial. Lancet Oncol 6: 659-668, 2005.

23. Tepper J, Krasna MJ, Niedzwiecki D, et al: Phase III trial of trimodality therapy with cisplatin, fluorouracil, radiotherapy, and surgery compared with surgery alone for esophageal cancer: CALGB 9781. J Clin Oncol 26: 1086-1092, 2008.

24. Fujiwara Y, Kamikonya N, Inoue T, et al: Chemoradiotherapy for T3 and T4 squamous cell carcinoma of the esophagus using low-dose FP and radiation: a preliminary report. Oncol Rep 14 $1177-1182,2005$.

25. Japanese Society for Esophageal Disease: Guidelines for Clinical and Pathologic Studies on Carcinoma of the Esophagus. 9th edition. Kanehara \& Co., Ltd., Tokyo, 2001.
26. National Cancer Institute: Cancer Therapy Evaluation Program, Common Toxicity Criteria. Version 3.0. http://ctep.cancer.gov/ protocolDevelopment/electronic_applications/ctc.htm., August 9, 2006

27. Courrech Staal EF, Aleman BM, Boot H, van Velthuysen ML, van Tinteren $H$ and van Sandick JW: Systematic review of the benefits and risks of neoadjuvant chemoradiation for oesophageal cancer. Br J Surg 97: 1482-1496, 2010.

28. Keller SM, Ryan LM, Coia LR, et al: High dose chemoradiotherapy followed by esophagectomy for adenocarcinoma of the esophagus and gastroesophageal junction: results of a phase II study of the Eastern Cooperative Oncology Group. Cancer 83: 1908-1916, 1998.

29. De Vita F, Di Martino N, Orditura M, et al: Preoperative chemoradiotherapy for squamous cell carcinoma and adenocarcinoma of the esophagus: a phase II study. Chest 122: 1302-1308, 2002.

30. Hsu FM, Lee JM, Huang PM, et al: Retrospective analysis of outcome differences in preoperative concurrent chemoradiation with or without elective nodal irradiation for esophageal squamous cell carcinoma. Int J Radiat Oncol Biol Phys 81: e593-e599, 2011.

31. Morota M, Gomi K, Kozuka T, et al: Late toxicity after definitive concurrent chemoradiotherapy for thoracic esophageal carcinoma. Int J Radiat Oncol Biol Phys 75: 122-128, 2009.

32. Onozawa M, Nihei K, Ishikura S, et al: Elective nodal irradiation (ENI) in definitive chemoradiotherapy (CRT) for squamous cell carcinoma of the thoracic esophagus. Radiother Oncol 92: 266-269, 2009

33. Zhao KL, Ma JB, Liu G, Wu KL, Shi XH and Jiang G: Threedimensional conformal radiation therapy for esophageal squamous cell carcinoma: is elective nodal irradiation necessary? Int J Radiat Oncol Biol Phys 76: 446-451, 2010.

34. Button MR, Morgan CA, Croydon ES, Roberts SA and Crosby TD: Study to determine adequate margins in radiotherapy planning for esophageal carcinoma by detailing patterns of recurrence after definitive chemoradiotherapy. Int J Radiat Oncol Biol Phys 73: 818-823, 2009.

35. Kranzfelder M, Schuster T, Geinitz H, Friess H and Buchler P: Meta-analysis of neoadjuvant treatment modalities and definitive non-surgical therapy for oesophageal squamous cell cancer. $\mathrm{Br} \mathrm{J}$ Surg 98: 768-783, 2011.

36. Ando N, Kato H, Igaki $\mathrm{H}$, et al: A randomized trial comparing postoperative adjuvant chemotherapy with cisplatin and 5-fluorouracil versus preoperative chemotherapy for localized advanced squamous cell carcinoma of the thoracic esophagus (JCOG9907). Ann Surg Oncol 19: 68-74, 2011.

37. Ando N, Iizuka T, Ide H, et al: Surgery plus chemotherapy compared with surgery alone for localized squamous cell carcinoma of the thoracic esophagus: a Japan Clinical Oncology Group Study - JCOG9204. J Clin Oncol 21: 4592-4596, 2003. 